\title{
Takeover Prediction Models and Portfolio Strategies: A Multinomial Approach
}

\author{
Ronan G. Powell \\ University of New South Wales, Australia
}

This paper uses a multinomial framework to develop several takeover prediction models. The motivation for this approach lies with Morck, Shleifer and Vishny (1988), who note that separate considerations are appropriate for predicting which firms are subject to hostile (disciplinary) and friendly (synergistic) takeovers in the USA. In a typical binomial setting, in which takeover targets are treated as belonging to one homogenous group, differences between hostile and friendly targets are ignored. This may result in biased takeover probabilities and poor predictive performance. Using UK data, the results from this paper show that the characteristics of hostile and friendly targets do differ, particularly in terms of firm size. The multinomial models also have higher significance and explanatory power when compared to the binomial models. Furthermore, when the models are tested in an investment portfolio setting, the results suggest that a strategy of predicting hostile targets only, beats a benchmark control portfolio of firms of a similar size and market-to-book (JEL G14, G34).

Keywords: multinomial logit, takeover prediction, abnormal returns, size effect

\section{Introduction}

One well documented motive for developing takeover prediction models is to use the predictions from such models to provide the basis for an investment strategy in which firms with high estimated probabilities of takeover are invested in; e.g., Wansley, Roenfeldt and Cooley (1983), Palepu (1986), and Powell (2001). The takeover literature has shown

\footnotetext{
${ }^{*}$ The author would like to acknowledge constructive comments received from participants at the 9th Annual Conference of the Multinational Finance Society, Cyprus. The paper has also benefitted from valuable comments received from the anonymous referees and the editor, Peter Theodossiou. Naturally, with respect to the paper, the usual caveat applies.
}

(Multinational Finance Journal, 2004, vol. 8, no. 1 \& 2, pp. 35-72)

(C) Multinational Finance Society, a nonprofit corporation. All rights reserved. DOI: $10.17578 / 8-1 / 2-2$ 
that for a target firm, the share price increases substantially (in some cases by as much as 50\%), from a period before the bid announcement date to the completion of the takeover; e.g., Jensen and Ruback (1983), and Franks and Harris (1989). If a model can be developed to predict takeovers in advance of the market, then holding a portfolio of predicted targets should result in the generation of abnormal returns. Naturally, however, the model's predictions will only be of use if it beats the market to the conclusion that a firm is a target. ${ }^{1}$

Wansley et al. (1983), Dietrich and Sorensen (1984), Palepu (1986), Barnes (1990 and 1999) and Powell (2001) all report models with impressive predictive ability. Predictability, however, does not imply abnormal returns can be earned. In fact, if the takeover probabilities generated by a prediction model are also known to the market, and are properly incorporated into share prices, then predictability and zero abnormal returns are perfectly consistent. Of these studies, only Wansley et al. (1983) provides evidence of significant and positive abnormal returns of $17 \%$ to a portfolio of 25 predicted targets over a holding-period of 21 months. Since target firms are significantly smaller in size than non-target firms (Palepu [1986], Powell [1997]), failure to adjust for this size effect (Banz [1981]) casts some doubt over the robustness of their abnormal returns. Using a size-adjusted model, Powell (2001) failed to find any evidence of significant abnormal returns to a portfolio of predicted targets identified using a binomial logit model. This would suggest that takeover probabilities generated by prediction models are already incorporated into share prices.

This paper re-examines the question of whether abnormal returns can be earned from a strategy of investing in firms predicted by a statistical model to be potential takeover targets. We extend the work of previous studies in three important areas. First, a multinomial logit model is employed to estimate separately the probability that a firm will be subject to either a hostile or a friendly takeover. Previous studies (e.g., Dietrich and Sorensen [1984], Palepu [1986], Barnes [1999], and Powell [2001]) generally use a simple binomial framework in which takeover targets are treated as one homogenous group (i.e., takeover targets). Research has shown, however, that modeling takeovers using a binomial framework may be misleading since takeovers may occur for many reasons. For example, on examining the characteristics of firms

1. In this paper, the term target refers to successful takeover targets. 
subject to takeover, Morck et al. (1988) and Powell (1997) note that separate considerations are appropriate for predicting which firms are subject to hostile (disciplinary) and friendly (synergistic) takeovers. Given this, it is likely that in a simple binomial setting in which target firms are treated as one homogenous group, much information may be lost. Using a multinomial framework, firms are classified not only according to whether or not the event took place, but also on the characteristics of the event (i.e., hostile or friendly). This should lead to a better model in terms of significance and explanatory power, which in turn, should help improve predictive ability.

Second, in selecting which firms to include in an investment portfolio, we employ a decision rule or cut-off probability set within the decision context of maximizing abnormal returns to the portfolio. Previous studies (e.g., Dietrich and Sorensen [1984] and Barnes [1990]) have either used arbitrary cut-off probabilities (e.g., 50\%) to select firms for inclusion in the portfolio or have derived the cut-off probability assuming, incorrectly, that the costs associated with the errors of misclassifying firms is equal and constant to Palepu (1986). This assumption is clearly incorrect when target firms are observed to earn large abnormal returns prior to takeover. If the objective of the prediction model is to earn abnormal returns, the appropriate portfolio decision rule should be derived on the basis of maximizing the proportion of target firms in the portfolio. Such a rule implicitly recognizes that the penalty associated with the misclassification of a non-target firm is significantly smaller than the pay-off from the correct classification of a target. The optimal cut-off probability is selected in this paper by examining the proportion of target firms in portfolios created from the estimation sample. The cut-off probability that maximizes the proportion of target firms in the estimation sample is then used to construct portfolio(s) from the prediction sample.

Third, this paper conducts a more rigorous analysis of the portfolios performance, including the use of several benchmarks (e.g., size and market-to-book) to calculate abnormal returns. This is important because the paper can be viewed as a joint test of the semi-strong form of the efficient markets hypothesis (EMH) and the benchmarks used to calculate the portfolio abnormal returns. The use of an inappropriate benchmark could result in the over rejection of the null hypothesis of no abnormal returns and hence a rejection of the EMH. This is a particular problem for studies of this type, where the sample firms, takeover 
targets, are generally smaller than the average firm in the population. Several simulation-type papers have documented the sensitivity of some benchmarks and asset pricing models to various sample specifications, including small firms; e.g., Barber and Lyon (1997), Kothari and Warner (1997), and Barber, Lyon and Tsai (1999).

The rest of the paper is organized as follows. The next section introduces the statistical models employed in estimating the probability of takeover for a firm. Section III describes the sample construction and data employed. Section IV briefly discusses the results of the estimated binomial and multinomial models. Section $\mathrm{V}$ outlines the procedures followed in constructing the portfolios. The performance of the portfolios is reported in section VI, and section VII concludes with a discussion and summary of the main points of the paper.

\section{Takeover Prediction Models}

This paper employs a multinomial logit model to estimate separately the probability that each firm in the population will be subject to a hostile or a friendly takeover. ${ }^{2}$ The multinomial logit model specifies the probability, $P_{i, j}$, that firm $i$ will belong to outcome $j$ (e.g., be a non-target if $j=0$, a hostile target if $j=1$ or friendly target if $j=2$ ) as a function of some row vector of measured characteristics, $X_{i}$, of the firm $i$. The model specified is as follows Maddala (1983):

$$
P_{i, j}=\frac{\exp \left(X_{i} \beta_{j}\right)}{1+\sum_{j=0}^{2} X_{i} \beta_{j}}
$$

where $\beta_{j}$ is a column vector of parameters to be estimated. In order to identify the parameters of the model, the normalization $\beta_{0}=0$ is imposed. The parameters of the model are estimated using maximum likelihood

2. The multinomial logit model employed in this paper is the general form model. This is to provide a distinction from the 'conditional' logit model developed by McFadden (1974) in the transportation literature. The main difference between the McFadden model and the general multinomial logit model adopted here, is that the McFadden model considers the effects of choice characteristics on the determinants of choice probabilities as well, whereas the general model makes the choice probabilities dependent on individual characteristics only Maddala (1983). 
within LIMDEP; see Greene (1991). The estimation procedure yields two sets of parameters; the first set representing hostile targets relative to non-targets and the second representing friendly targets relative to non-targets. The probability that a firm will be either a hostile or a friendly target can then be evaluated by applying equation 1 . A binomial model in which hostile and friendly targets are treated as belonging to one homogenous group is also estimated for comparison purposes.

Four logit models are estimated. The four models can first be distinguished by whether they aggregate targets into a single group or treat hostile and friendly targets as separate. The models which treat targets as a single group (i.e., binomial) are denoted B1 and B2 and the models which separate hostile and friendly takeovers into separate groups (i.e., multinomial) are denoted M1 and M2. The second distinction between the models estimated is the variables included in the model. Models B1 and M1 use only firm values for characteristics examined as independent variables. Models B2 and M2 use industry-relative ratios, where firm values are scaled by industry-weighted values and industry-weighted values are scaled by economy-weighted values. ${ }^{3}$ Since financial ratios are likely to vary both over time (e.g., through changes in price levels, accounting policies, and the business cycle; Platt et al. [1994]) and across industries, re-scaling the variables should go some way to improving stability. A good prediction model is one that remains stable both over time and across all industries. Barnes (1990) and Platt and Platt (1990) recommend the use of industry-relative ratios in prediction studies to help alleviate the data instability problem. ${ }^{4}$

The variables employed in estimating the models represent six takeover theories. ${ }^{5}$ These theories are chosen because they have been

3. In order to avoid the survivorship bias problem common to Datastream industry averages (see Powell [1997], footnote 8) the true population of firms for each year was re-constructed and used to calculate the appropriate value weighted industry and economy averages for each of the variables used in the study. The industry affiliation of the firms is that used by the Financial Times All Share index (Datastream, classification level 4).

4. Addressing the stability problem is of particular importance in this study due to the pooled estimation sample over a 10-year period (1986-95). It is highly unlikely that financial ratios remain stable over this time period, so the use of industry-relative ratios should in some way help address this problem.

5. The approach typically used to date in selecting variables for prediction models is to select a large number of variables on an ad hoc basis and examine their usefulness in the model through some filtering mechanism such as factor analysis or stepwise refinement; e.g., 
frequently and consistently documented in the literature as explanations for takeovers; e.g., Palepu (1986), Ambrose and Megginson (1992) and Barnes (1999). The theories include the replacement of inefficient management, firm undervaluation, free cash flow, firm size, real property and growth-resource imbalance. The takeover theories and the variables used to proxy them are briefly summarized below.

\section{A. Replacement of Inefficient Management}

This takeover motive argues that takeovers are a mechanism by which managers of a firm who fail to maximize its market value are replaced by more efficient managers. Here, the threat of takeover provides a useful mechanism for encouraging managers to pursue shareholder wealth maximization strategies. Firms with inefficient managers are likely to suffer from poor performance. Several studies have shown poor performance as measured by share price and accounting rates of return to be a characteristic of target firms; e.g., Asquith (1983) and Kennedy and Limmack (1996).

In this paper, the accounting return on capital employed (ROCE) is used to proxy managerial performance. The ROCE is computed and averaged over a period of two years prior to the observation year. The observation year is defined for a target firm as the year in which it is taken over, and for a non-target firm, the year in which it is observed not to be taken over.

\section{B. Firm Undervaluation}

Firms who possess a low market-to-book (MTB) ratio are likely to be targets. Under this scenario, a low MTB ratio signals undervalued or under-utilized assets. By seeking out firms with low MTB ratios an acquiring firm captures 'cheap' assets. The appropriate measure to use for this purpose is the ratio of the market value of a firm to the replacement cost of its assets, a ratio usually known as 'Tobin's q'. The lower $\mathrm{q}$ is, the higher the likelihood of a potential acquirer preferring to acquire the firm rather than start afresh; see Hasbrouck (1985).

In this paper, the MTB ratio is used as a proxy for $q$ because replacement costs were not consistently produced by UK firms during

Barnes (1990). Palepu (1986), p.16, however, argues that this approach 'is arbitrary and leads to statistical over-fitting of the model to the sample at hand.' 
the period covered by the study. The MTB ratio is calculated as at the accounting year-end prior to the observation year.

\section{Free Cash Flow}

Free cash flow (FCF) is 'cash flow in excess of that required to fund all projects that have positive net present value when discounted at the relevant cost of capital' (Jensen [1986], p. 321). The theory predicts that firms with incompetent management teams that have performed poorly, and firms that have done exceptionally well and have accumulated large FCFs that are not returned to investors, are the most likely targets. This theory has received empirical support from Palepu (1986) and Lehn and Poulsen (1989).

The ratio of operating cash flow to total assets is used to proxy FCF. ${ }^{6}$ The ratio is computed and averaged over a period of two years prior to the observation year.

\section{Firm Size}

This theory suggests that takeover likelihood decreases with firm size. The theory is based on the premise that there are transaction costs of takeovers related to size making it more difficult for potential bidders to absorb large firms. The firm size theory of takeovers has probably received the most consistent support in the takeover literature; e.g., Levine and Aaronovitch (1981), Palepu (1986) and Ambrose and Megginson (1992).

The log of total assets (SIZE), as a measure of the size of the firm, is included in the models. SIZE is measured as at the year-end prior to the observation year.

\section{E. Real Property}

Firms with a high percentage of tangible fixed assets in their total asset structure are thought likely takeover targets; see Ambrose (1990). One explanation for this effect is that tangible fixed assets could be a proxy

6. Since our measure of FCF is rather crude, it is possible that it may simply be a proxy for firm performance and not FCF. If this is the case, we should expect a high correlation between our measures of FCF and ROCE. The correlation between the variables is 0.40 using raw variables and 0.33 using industry-relative ratios, which suggests that the definition of cash flow used is a reasonable proxy for FCF and not performance. 
for greater debt-capacity; see Stulz and Johnson (1985). A bidding firm could use the target's own assets as security for debt financing of the takeover, thereby effectively lowering the direct cost to the acquiring firm. Furthermore, firms with a high proportion of tangible fixed assets make ideal candidates for asset striping by 'raiders', Eddey (1991).

The ratio of tangible fixed assets to total assets (TNG) is computed and averaged over a period of two years prior to the observation year.

\section{F. Growth-Resource Imbalance}

Growth, liquidity and leverage variables are also included in the estimated models. These variables have been used by several studies, (e.g., Palepu [1986]; Ambrose and Megginson [1992]; and Powell [1997]) and appear to be potentially important variables in determining the likelihood of takeover. One motive for takeover may be the existence of a growth-resource imbalance in the target. For example, high growth firms with low resources (i.e., low liquidity and high leverage) may be targeted by acquiring firms with the opposite growth-resource imbalance (i.e., low growth, resource rich). Also, low growth firms with high resources may be targeted by acquiring firms with the opposite growth-resource imbalance (i.e., high growth, resource poor) so as to take advantage of the excess cash flows of the target. By acquiring a firm with the opposite growth-resource imbalance, the value of the combined firms should exceed the value of the two firms separately.

Growth (GRO) is measured as average sales growth over the period of two years prior to the observation year. ${ }^{7}$ Liquidity (LIQ) is measured as the ratio of cash and marketable securities to total assets, and leverage (LEV) is measured as the ratio of debt to the total share capital and reserves. Both these latter variables are averaged over two years prior to the observation year. A dummy variable (GRDUMMY) is used to test the growth-resource imbalance. The GRDUMMY is assigned a value one for firms that have either growth resource imbalance and zero for all other combinations. Growth, liquidity and leverage are

7. The use of growth in sales revenue as a proxy for firm growth is common in prior empirical papers; see Palepu (1986), Theodossiou et al. (1996), Barnes (1998) and Powell (2001). Sales revenues as a measure of growth could, however, be problematic in that it could potentially mask an aggressive discounted pricing policy of the firm that actually produces a decline in operating performance. If target firms are more likely to pursue aggressive pricing policies prior to takeover, the results for firm growth may be biased. 


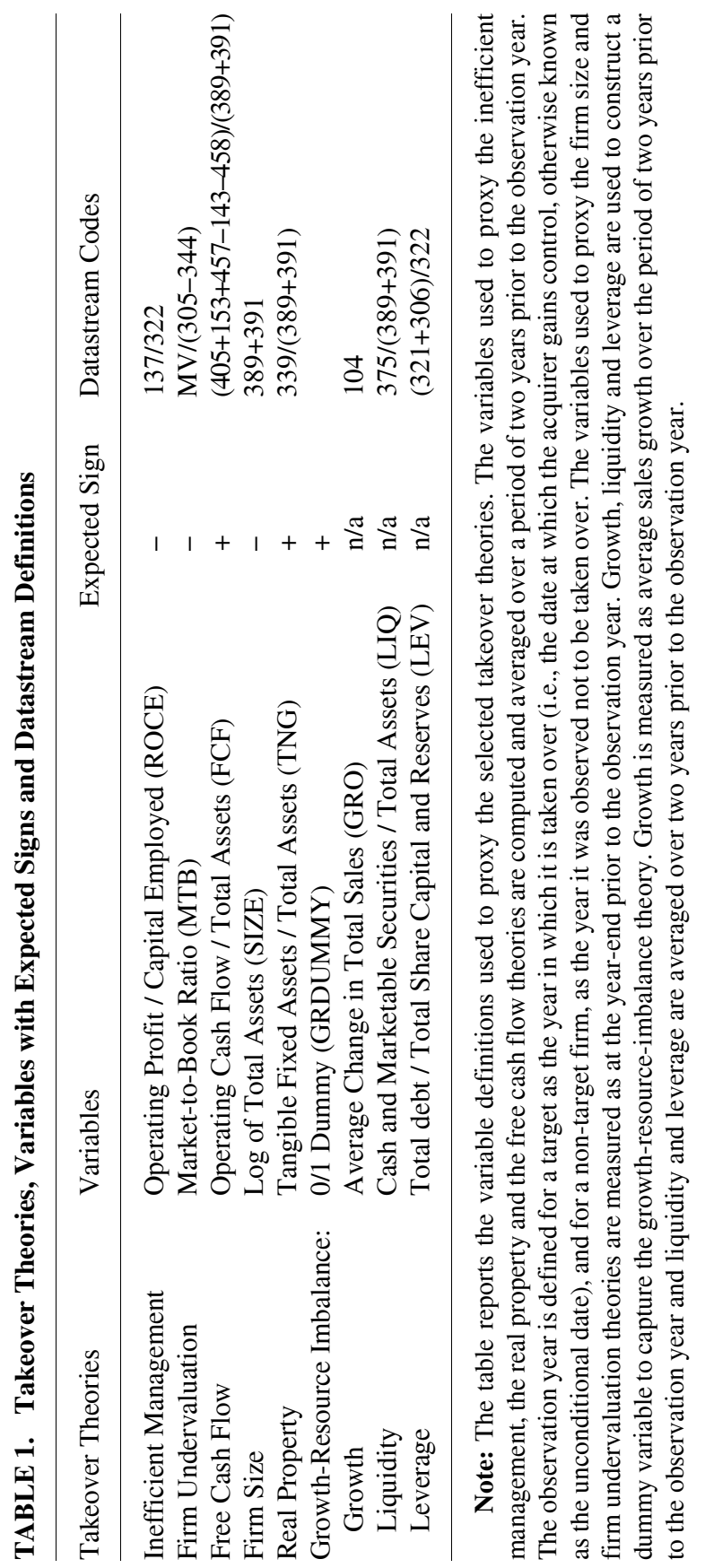


considered high (low) if the value for a firm is higher (lower) than the firm's industry average. The firm characteristics employed as variables in the takeover models are summarized in table 1.

\section{Sample Construction}

The estimation sample comprises the pooled population of firms that existed each year between 1986 and $1995 .{ }^{8}$ To be included in the sample a firm must (i) not belong to a financial sector defined by Datastream classification level 4; (ii) be listed on the London Stock Exchange (LSE); and (iii) have three years of company accounts data stored on Datastream. ${ }^{9}$ This gives a total sample of 9,891 firm-year observations, with an average of 990 firms per year. We track the population of firms for each year through to the end of 1995 to determine the number of successful takeovers. Target firms are identified from Acquisitions Monthly, published by Thomson Financial. 471 firms were successfully taken over by the end of 1995; see table 2. As expected, most of the takeovers occurred during the 1980s boom period (1986-89). On average, however, takeovers only account for about 5\% of the population each year.

The targets are partitioned according to whether the takeover was hostile or friendly. A hostile target is defined as one where the target management rejects the initial bid from the acquiring firm; otherwise the takeover is defined as friendly. Of the 471 targets, 81 are defined as hostile and 390 as friendly. Note that this definition could result in misclassification errors in classifying hostile and friendly takeovers. For

8. Previous studies have generally used matched-based or choice-based samples, which give rise to equal numbers of targets and non-targets in the estimation sample. While there might be some merit in this approach in terms of improving the models' explanatory power (see Palepu, 1986), a choice-based sample does not reflect the true proportions of takeovers in the population. Other studies, such as Ambrose and Megginson (1992), use a different sampling scheme whereby starting from a particular time period, you first establish the population of firms, select a random sample from this population and track these firms across the sample period. While this approach has some merit, it fails to account for new firms that join the population each year in the form of initial public offerings. Furthermore, by ignoring new firms, the proportion of target firms in the sample may not be representative of the population. For example, Ambrose and Megginson (1992) report an average target proportion of $28 \%$ over a 6 -year period, which is significantly larger than the $5 \%$ reported in this paper.

9. Three years of data is required since it is the minimum number of years necessary to compute the average sales growth ratio. 


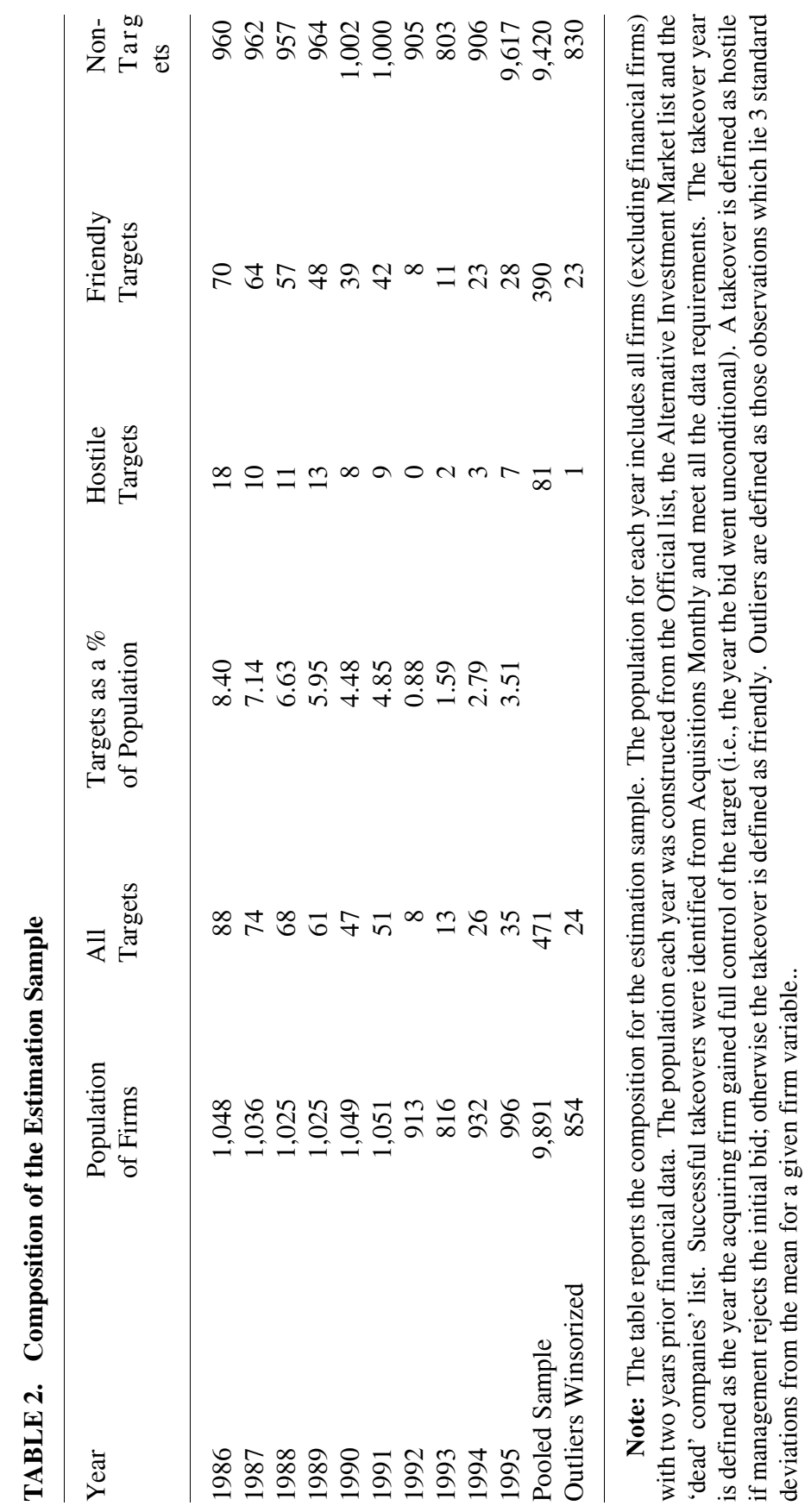


example, target management may reject an initial bid in an attempt to encourage the acquiring firm to bid up the price. In this case, bids that appear hostile may, in fact, be friendly. In the same light, some friendly takeovers may in fact be hostile simply because target management may feel it futile to oppose the bid since it perceives its success as inevitable (e.g., the bidder may be much larger in terms of physical size, have a highly skilled management and advisory team, and have a reputation for winning bids). While the definition used is not perfect, it has been used widely in prior research. For example, Schwert (2000) uses several definitions of hostility, but finds a stronger correlation between hostility defined as the initial rejection by target management sourced from both the Wall Street Journal and the SDC database. Similarly, the definition has been employed by Cosh and Guest (2001) and Powell and Stark (2003) in measuring the impact of bid hostility on post-takeovers gains to acquiring firms.

An alternative definition of hostility, which would potentially minimize misclassification errors, is to examine the ex-post departure rates of top management for the target firm. If key top managers are removed, it is more likely the takeover is hostile. Using UK data, Franks and Mayer (1996) investigate departure rates for a period of up to 2 years following successful takeover. They report a board turnover rate of $90 \%$ for successful hostile takeovers, indicating that hostile takeovers play a disciplining role in removing inefficient managers. Similar findings are reported by Dahya and Powell (1998), using a larger sample and a different time period. The high correlation between hostile takeovers (defined as the target management's rejection of the initial bid) and top management turnover provides some additional comfort that the definition of hostility employed in this paper is reasonable in partitioning the sample into hostile and friendly sub-samples. ${ }^{10}$

Of the 9,891 firm-year observations, 854 (24 targets and 830 non-targets) are identified as outliers. Outliers are defined as those observations that lie \pm 3 standard deviations from the mean for a given variable. To avoid deleting these observation we winsorize them back to \pm 3 standard deviations from the mean. ${ }^{11}$

10. Defining hostility in terms of top management turnover would be difficult to operationalize in this paper since board turnover data may not be publicly available at the time of estimating the model(s). For example, board turnover data is unlikely to be available for takeover targets for the last year of the estimation sample.

11. Of all the variables used to estimate the models, the market-to-book ratio caused the greatest number of outliers, accounting for some 400 firm-year observations. This was partly due to the large number of negative market-to-book ratios caused by negative book values. 


\section{The Characteristics of Takeover Targets}

The results of the four logit models are presented in table 3. A positive sign on a coefficient indicates that an increase in the corresponding variable increases the likelihood of takeover and a negative sign indicates the opposite.

Table 3 also reports the significance (likelihood ratio) and the explanatory power (McFadden $\mathrm{R}^{2}$ ) of the models. Two observations can be made. First, the inclusion of industry-weighted and economy-weighted variables greatly improves the significance and explanatory power of the models. For example, comparing the binomial models, model B2 has the highest likelihood ratio (52.76, with 17 degrees of freedom) and $\mathrm{R}^{2}(1.46 \%) .{ }^{12}$ Second, modelling takeovers in a multinomial framework improves the models overall significance and explanatory power. Comparing model M2 to model B2, the likelihood ratio increases by approximately 47 and the explanatory power by approximately $1 \%$.

In terms of target characteristics, the binomial models indicate that smaller firms with lower liquidity run the highest likelihood of being taken over. A significant and positive sign on the growth-resource dummy (GRDUMMY) indicates that firms with a growth-resource imbalance are likely to be targeted for takeover. These results are generally consistent with Palepu (1986) and Powell (1997). The negative and positive signs on the liquidity and leverage coefficients, respectively, indicate that targets exhibit a resource-poor imbalance. Palepu (1986) found the opposite growth-resource imbalance, that is, lower growth, resource rich firms were more likely to be acquired. Firm size, liquidity and leverage are given further support using firm-specific variables (model B2). Examining the industry characteristics indicates that the likelihood of takeover increases for firms that belong to higher growth industries with lower leverage.

The multinomial models suggest that the characteristics of hostile and friendly targets are different, particularly in terms of firm size. Model M1 suggests that hostile takeovers tend to be directed more

12. The explanatory power of the models is generally quite low compared to previous studies. For example, Palepu's best model reports an $\mathrm{R}^{2}$ of $12.5 \%$. The low explanatory power can be explained by the differences in the size of the estimation samples. Palepu's sample of 163 targets and only 256 non-targets is not representative of the true proportion of targets in the population. By increasing the proportion of targets in his sample, he was able to increase the explanatory power of his models. 


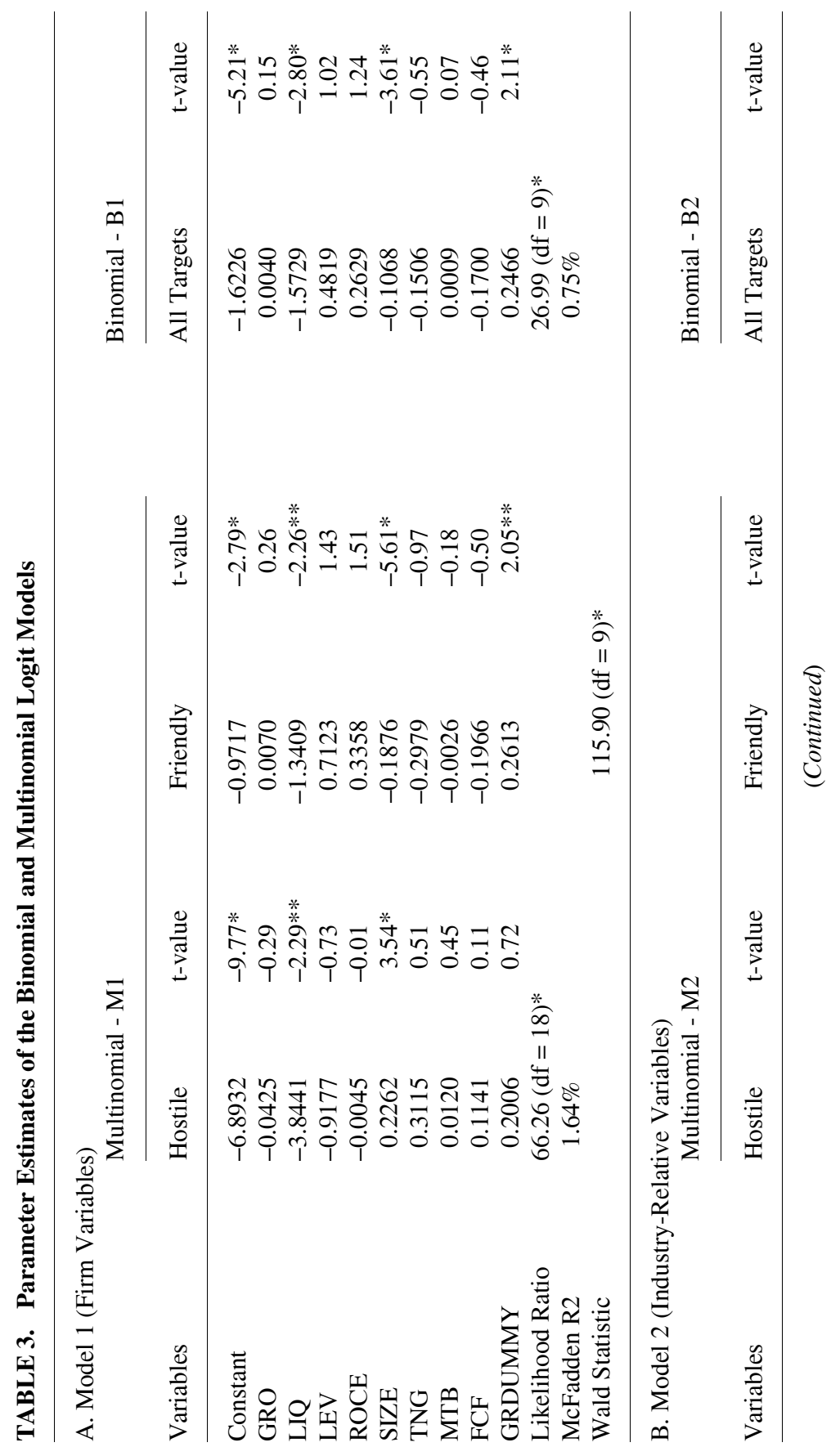




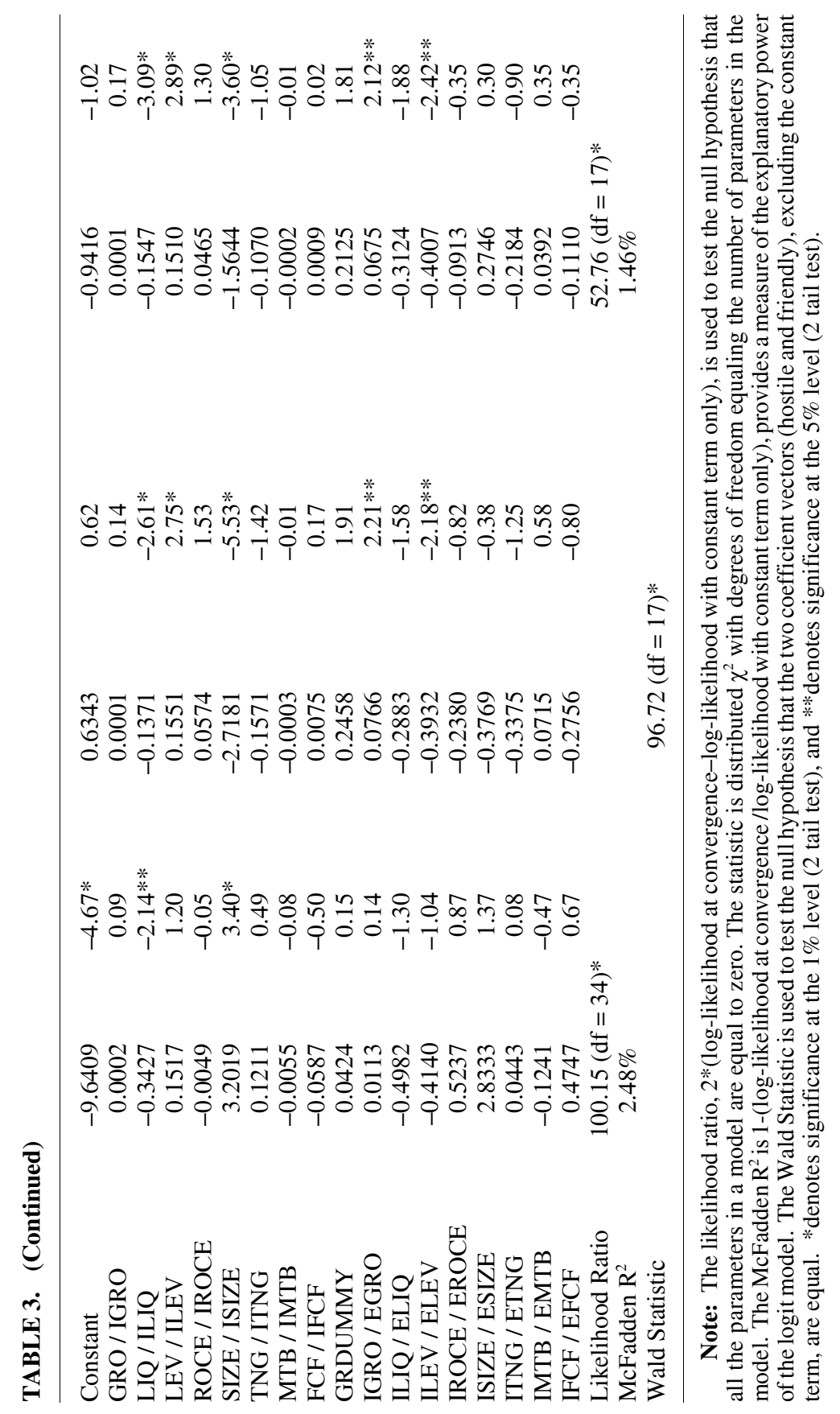


towards larger firms with lower liquidity, consistent with Powell (1997). Friendly takeovers, on the other hand, tend to be directed more towards smaller firms with a growth-resource imbalance. Industry characteristics seem to play some role in explaining friendly takeovers. In particular, all the significance in the industry growth and leverage variables in the binomial model (model B2) can be attributed to friendly takeovers. Furthermore, the Wald statistic, which tests the null hypothesis of no difference in the vector of coefficients for hostile and friendly takeovers, is highly significant for both models, suggesting that hostile and friendly takeovers are different. This indicates that the binomial models may be misspecified since they fail to account for the differences in hostile and friendly takeovers. Whether this has any impact on predictive power will be examined in the next section.

\section{Portfolio Construction}

This section describes the procedures followed in arriving at an optimal cut-off probability for each of the models. The out-of-sample predictive ability of the models on the true population of firms is then reported.

\section{A. Within Sample Optimal Cut-Off Probabilities}

The selection of firms for inclusion in a portfolio is usually made on the basis of some classification rule. ${ }^{13}$ Several papers have used arbitrary classification rules, such as classifying all firms with a probability equal

13. In applying the classification rule, the estimated probability assigned to a firm is compared to the cut-off probability. If the estimated takeover probability exceeds the cut-off, the firm is classified as a target; otherwise it is classified as a non-target. For hostile takeovers, if a firm's takeover probability is greater than the cut-off, the firm is classified as a hostile target; otherwise the firm is classified as a non-target. Since we are predicting the probability of a hostile takeover, the non-target sample will include friendly takeovers. The same procedure is applied when predicting the probability of a friendly takeover for a firm. Here, the non-target sample will include hostile takeovers. Hence, this classification scheme is binomial in a sense. Such a scheme seems reasonable since it may be more beneficial to predict one type of takeover, particularly if one type of takeover is more easily identifiable (predictable) from the total population (refer to the appendix for the differences in the distribution of hostile and friendly targets). Furthermore, the literature has shown that the gains to hostile targets are greater than those to friendly targets, in some cases by as much as 10\%; see Franks and Mayer (1996). Hence, in a portfolio setting, one would want to include as many hostile targets as possible. Predicting hostile and friendly targets separately directly addresses these issues. 
to or greater than $50 \%$ as targets. This may be acceptable in cases where the sample is match-based with equal numbers of target and non-targets firms. Such samples, however, are not representative of the true population proportions of targets and non-targets (see table 2) and so it is difficult to interpret the classification accuracies.

In Palepu (1986), the classification rule was derived by minimizing the total number of misclassifications. The calculation of an optimal classification rule (or cut-off probability) amounts to a trade-off between the marginal cost of committing a type I error (a target incorrectly classified as a non-target) or a type II error (a non-target incorrectly classified as a target). Palepu assumed, like most previous studies, that the costs of type I and type II errors are equal and constant.

This assumption is, however, unrealistic since the gains to target firms prior to takeover far exceed those to firms not taken over (Jensen and Ruback, 1983). The penalty for the misclassification of a non-target firm would thus be significantly smaller than the pay-off from the correct classification of a target. Hence, if the objective is to maximize the abnormal returns of a portfolio, then the costs are neither equal nor constant. ${ }^{14}$

Theodossiou et al. (1996) derive a classification rule based on minimizing their model's expected cost function. Specifically, the optimal classification rule (cut-off probability) is given as:

$$
\min E(C)=W_{T} \text { type I }+W_{N T} \text { type II }
$$

where $W_{T}$ and $W_{N T}$ are investors' specific weights attached to type I and type II errors, respectively. The weights should be set so as to reflect differences in the costs associated with type I and type II errors and the a priori probability of being taken over or not taken over. Clearly, $W_{T}=$ $P_{T} C_{T} /\left(P_{T} C_{T}+P_{N T} C_{N T}\right)$ and $W_{N T}=P_{N T} C_{N T} /\left(P_{T} C_{T}+P_{N T} C_{N T}\right)$, where $P_{T}$ and $P_{N T}$ reflect the a priori probability of being taken over or not

14. For example, assume that one firm has been placed in a portfolio that is equally weighted. Let this firm actually become a target and earn the average abnormal return for targets, $r$. If the next firm placed in the portfolio is not acquired (a type II error), it earns zero abnormal returns. Now, the portfolio abnormal return is $\mathrm{r} / 2$, resulting in an incremental loss of $r / 2$. If the third firm is also a type II error, this will reduce the portfolio abnormal return to $\mathrm{r} / 3$, which is an incremental loss of only $r / 6$. Clearly the loss on misclassification is not constant. Furthermore, if we assume instead that after the first firm, a correctly predicted target is placed in the portfolio, there is a type I error excluded that earns $r$. The cost of this error is $\mathrm{r}$, compared to $\mathrm{r} / 2$ for the type II error, so the losses are not equal either. 
taken over in the population, respectively, and $C_{T}$ and $C_{N T}$ are the associated costs of type I and type II errors, respectively. While Theodossiou et al. (1996), recognize that the cost of committing a type I error is greater than the cost of committing a type II error and that the probability of being taken over is significantly lower than not being taken over, they employ an equal weighting scheme (i.e., $W_{T}=W_{N T}=$ $0.5)$, arguing that this is reasonable in the absence of specific weights. By using an equal weighting scheme, $E(C)$ gives the model's average error rate, which is similar (i.e., will give the same cut-off probability) to Palepu's classification rule of minimizing the total error rate.

In a choice-based sampling scheme, such as that used in Palepu, 1986 and Theodossiou et al. (1996), of approximately equal numbers of targets and non-targets, such a rule would result in a low cut-off probability, since equal weight is applied to both type I and type II errors. By applying a low cut-off probability, Palepu increased the number of non-target firms incorrectly classified as targets (type II error) in his portfolio. For example, Palepu's portfolio comprised of 625 firms, of which only 24 were in fact targets. In this case, any significant abnormal returns to the small number of actual target firms in the portfolio would be diluted by the near zero abnormal returns of the large number of firms not taken over.

In an estimation sample that reflects the true proportion of targets in the population, Palepu's rule, however, would lead to an extremely high cut-off probability. In fact, at the extreme, the rule would result in misclassifying all target firms as non-targets (type I error) since equal weight is applied to both type I and type II errors. For example, using our estimation sample to illustrate, which comprises of 9,891-firm years, of which 471 are targets and 9,420 (=9,891-471) are non-targets. If we use Palepu's classification rule, that is, maximize the percentage of correct classifications (or minimize the total number of misclassifications), this will occur at the point where all 471 targets are misclassified as non-targets. That is, the cut-off probability will be such that all 9,420 non-target firms are correctly classified (see the appendix, panel A and B), which will occur at a cut-off probability of $95.24 \%$ $(9,420 / 9,891)$. Clearly, this would result in a portfolio comprising of zero firms.

If the objective of the estimated model is to earn abnormal returns, then the optimal portfolio selection criterion should be to maximize the proportion of target firms in the selected portfolio rather than minimizing the absolute number of misclassifications, as is typically 
done in prediction studies. This is operationalized by calculating the takeover probabilities for each firm in the estimation sample and constructing portfolios by dividing the minimum and maximum probabilities into deciles. The portfolio (and cut-off) that provides the highest proportion of targets is then used in the prediction tests. Using this rule implicitly recognizes that the penalty of misclassifying a target firm as a non-target (type I error) is significantly larger than misclassifying a non-target as a target (type II error). Furthermore, deriving the cut-off probability using this decision rule implicitly sets the cut-off probability within the decision context of maximizing abnormal returns to the portfolio. ${ }^{15}$

The appendix reports the optimal cut-off probability and within sample discrimination ability of the models. Naturally, a priori, only one model and cut-off (the optimal cut-off) can be chosen to predict future targets for portfolio selection. The optimal cut-off is denoted in each table by bold-type.

Two observations can be made from the appendix. First, the differences in the optimal cut-off probability using the different decision rules. As expected, using Palepu's rule of maximizing the percentage of total correct predictions, the optimal cut-off always lies at the last decile, where all targets (hostile or friendly) are misclassified as non-targets (type I error). Using the rule adopted in this paper results in lower cut-offs and portfolios with a higher proportion of targets (denoted in bold type). Second, the difference in the distribution of hostile and friendly targets is quite large, due to hostile targets having a much lower takeover probability compared to friendly targets. This further supports the use of a multinomial framework.

Given our discussion above, the within sample discrimination ability does not tell us much about the classification ability of the models since, due to the nature of the estimation sample, classification will always be maximised at the point where all targets are misclassified as non-targets. Furthermore, the within sample discrimination ability of the models is of little interest since it tells us little about the actual predictive ability of the models. Also, the model parameters and cut-off probabilities are obtained from the estimation sample. Any test based on this sample is, therefore, likely to be biased.

15. Maximizing the proportion of target firms in the portfolio is equivalent to maximizing abnormal returns to the portfolio. For example, assuming that targets, t generate abnormal returns of $r$ and non-targets, nt earn zero abnormal returns. The optimal cut-off probability will occur at the point (or decile) that maximizes $r$, i.e., $(\mathrm{t} * \mathrm{r} / \mathrm{t}+\mathrm{nt})$. 


\section{B. Predictive Ability of the Models}

In this paper, portfolios of predicted targets are formed on 1 January 1996. The population of firms at this date is therefore used to test the true predictive ability of the models. ${ }^{16}$ After meeting the criteria for inclusion in the study, 1,000 firms have the required data, 29 (4 hostile and 25 friendly) of which were actually acquired by the end of December 1996. The estimated parameters from each of the estimated logit models are used to compute the takeover probability for each firm in the population. Portfolios are formed by applying the optimal cut-off probabilities reported in the appendix. The predictive performance of the models is reported in table 4.

In the context of this paper, the true test of the models power is whether they are able to clearly identify target firms from the total population. If the models achieve this, we should be able to earn significant abnormal returns from the investment strategy of investing in all firms predicted by the models to be future takeover targets. It is clear from table 4 that the models fail to clearly identify target firms from the total population. For example, using the optimal cut-offs reported in the appendix for model B2 (panel B), 42 firms are predicted as potential targets, where in fact only 2 (or $4.76 \%$ ) are acquired by the end of December 1996. Model B1 (panel A), on the other hand, predicts no firms as future takeover targets, probably due to the lower significance and explanatory power of this model. In comparison to a random choice alone, 2.9\% (29 acquired / 1000; total population) of firms have the potential to be acquired, implying that model B2 is marginally better than a random selection.

Several observations can be made about the multinomial logit models. First, when hostile and friendly targets are predicted separately, there seems to be a higher success rate at predicting hostile targets

16. In the UK, companies have a maximum of six months from their financial year-end to publish their financial statements. To avoid the possibility that data used in the estimation of the model(s) may not have been publicly available, all variables are measured from the two years prior to the observation year. For example, all ratios for 1995 firms are averaged from year-ends 1994 and 1993. To create the population on January 1st 1996, variables are averaged over 1995 and 1994 accounting year-ends. Note that for some firms, financial data (in particular, for those firms with December 1995 year-ends) may not have been publicly available on 1 January 1996. Naturally, this will bias the results in favor of finding abnormal performance, when in fact none may exist. Since most firms publish their annual reports within three months of the year-end, simply ignoring the abnormal performance for the first three months of the holding period should control for this potential bias. 
compared to friendly targets. For example, using the optimal cut-off probabilities, both models M1 (panel C) and M2 (panel E) successfully predict $3(75 \%)$ and $2(50 \%)$ hostile targets, respectively. This compares favourably with the friendly models, which fail to predict any targets using model 1 (panel D) and only 2 (8\%) using model 2 (panel F). Second, when we combine the hostile and friendly predictions of models 1 and 2 to form 2 combined portfolios, the results can be compared to the binomial models. The results indicate that the multinomial models significantly outperform the binomial models in terms of the percentage of targets correctly predicted. Model M1 (M2) correctly predicts $48 \%$ $(28 \%)$ of targets compared to no targets predicted using model B1 and only $7 \%$ using model B2. ${ }^{17}$ Clearly, the use of a multinomial framework, where hostile and friendly targets are predicted separately, leads to a higher success rate in predicting targets. Third, the models still misclassify a high proportion non-target firms as targets (type II error), which, from an investment perspective, is likely to significantly dilute the abnormal returns from the targets correctly predicted. For example, of the 268 firms predicted by model M2 to be hostile (friendly) targets, only 8 (3\%) are actually acquired by 31 December 1996.

\section{Portfolio Abnormal Returns}

This section describes the procedures followed in calculating abnormal returns to the predicted portfolios. Monthly returns for each firm in each portfolio are calculated using Datastream's returns index (data-type RI). The returns index is calculated on the assumption that gross dividends are re-invested at the ex-dividend date, so ignores tax and re-investment charges. Buy-and-hold abnormal returns $(B A H A R)$ are defined in a manner similar to Barber et al. (1999). ${ }^{18}$ First, they are calculated as the

17. Models M1 (M2) correctly predict 3 (2) hostile and 0 (2) friendly targets correctly, giving a total of 3 (4) targets. However, model M1 (M2) also misclassify 11 (5) friendly targets as hostile targets and $0(1)$ hostile targets as friendly targets. Combining the portfolios of hostile and friendly targets for both models gives $14(3+0+11)$ targets for model M1 and $9(2+2+5)$ targets for model M2. However, for model M2, both models predicted 1 firm as both hostile and friendly, so the combined portfolio has actually 8 targets and not 9 . This gives the percentage of targets predicted as $48.28 \%$ (14/29) for model M1 and 27.59\% (8/29) for model M2.

18. Barber et al. (1999) advocate the use of buy-and-hold abnormal returns, which they argue give rise to well specified test statistics. Generally, buy-and-hold abnormal returns, as opposed to cumulative abnormal returns, control for the new listing, re-balancing and skewness biases, which give rise to mis-specified test statistics. 
difference between the return on a firm in the predicted portfolios and the return on a control portfolio, matched by firm size. Second, they are calculated as the difference between the return on a firm in the predicted portfolios and the return on a control portfolio, matched by firm size and market-to-book ratio. The use of these benchmarks is important and necessary when the sample of event securities is unrepresentative across any extra-market dimension, in this case, size and market-to-book. It is well documented in the literature that smaller firms and firms with lower market-to-book ratios earn higher returns; see Fama and French, (1992) and Barber and Lyon (1997). Furthermore, the literature on takeovers and the results presented in table 3 show that target firms in general are smaller in size compared to firms not taken over, re-enforcing the need for an appropriate benchmark.

With this approach, the BAHAR for security $j$ for a holding-period $T$, where $T=12,24$ or 36 -months, is given as:

$$
B A H A R_{j, T}=R_{j, T}-R_{c, T}
$$

where $R_{j, T}$ is the period buy-and hold return for firm $j$ for period $T, R_{c, T}$ is the buy-and hold return on a similar size or size and market-to-book matched control portfolio for period $T$. To identify the matched control portfolios we follow two steps. First, we first rank all firms on the LSE by their equity market values as at January, 11996 and create 10 size control portfolios. Second, we partition each size control portfolio into 5 market-to-book quintiles, creating a total of 60 control portfolios (10 size and 50 size/market-to-book). Since we are adopting a passive buy-and-hold strategy, we first compound the returns on all firms in each portfolio over the holding period and then average across firms to arrive at the benchmark portfolio return.

The predicted portfolios are formed on January 1, 1996 and held for periods of 12, 24 and 36 months. Following Barber et al. (1999), abnormal performance is defined as the cross-sectional average of the period buy-and-hold portfolio abnormal returns. ${ }^{19}$ The BAHAR for a

19. Naturally, not all firms survive the portfolio holding periods due to takeover or bankruptcy. For these firms, abnormal performance is measured over the months they survived. So, for example, if a firm in a portfolio is acquired within the 12-month holding period, say month 8 , only the returns up to month 8 will be included in the BAHAR. Naturally, the proceeds from this takeover could be reinvested in the portfolio. However, this would breach the assumption of a passive buy-and-hold strategy. 
portfolio $p$ of $N$ firms over a holding period $T$ is

$$
\operatorname{BAHAR}_{p, T}=\frac{1}{N} \sum_{j=1}^{N} B A H A R_{j, T},
$$

where

$$
B A H A R_{j, T}=\prod_{t=1}^{T}\left(1+R_{j, T}\right)-\prod_{t=1}^{T}\left(1+R_{c, T}\right)
$$

and $T=12,24$ and 36 . The test statistic is given by

$$
\frac{\text { BAHAR }_{p, T}}{\sigma\left(\text { BAHAR }_{p, T}\right) / \sqrt{N}}
$$

and the cross-sectional standard deviation of the mean BAHAR for portfolio $p$ for a holding period $T$ is:

$$
\sigma\left(B A H A R_{p, T}\right)=\frac{1}{N}\left[\sum_{j=1}^{N}\left(B A H A R_{j, T}-B A H A R_{c, T}\right)^{2}\right]^{0.5} .
$$

If each firm's BAHAR is independent and identically distributed, then the test statistic should be approximately unit normal.

Table 5 reports the BAHAR for each of the estimated models for holding periods of 12, 24 and 36-months using both size and size to market-to-book benchmarks. Several observations can be made. First, the results for the binomial models (B1 and B2) indicate that on average, the models earn abnormal returns insignificantly different from zero. In fact, for model B2 (panel B), the results indicate that investing in a portfolio of predicted targets would actually result in significant losses as the holding period increases from 12 to 36 -months. Second, the results suggest that the use of a multinomial framework greatly improves the chances of identifying a portfolio capable of generating positive abnormal returns. This result is not too surprising given the higher success rate of the multinomial models at identifying target firms. In particular, the results suggest that a strategy of predicting hostile targets will result in a portfolio of significant abnormal returns, if held for a period of more than twelve months. The 


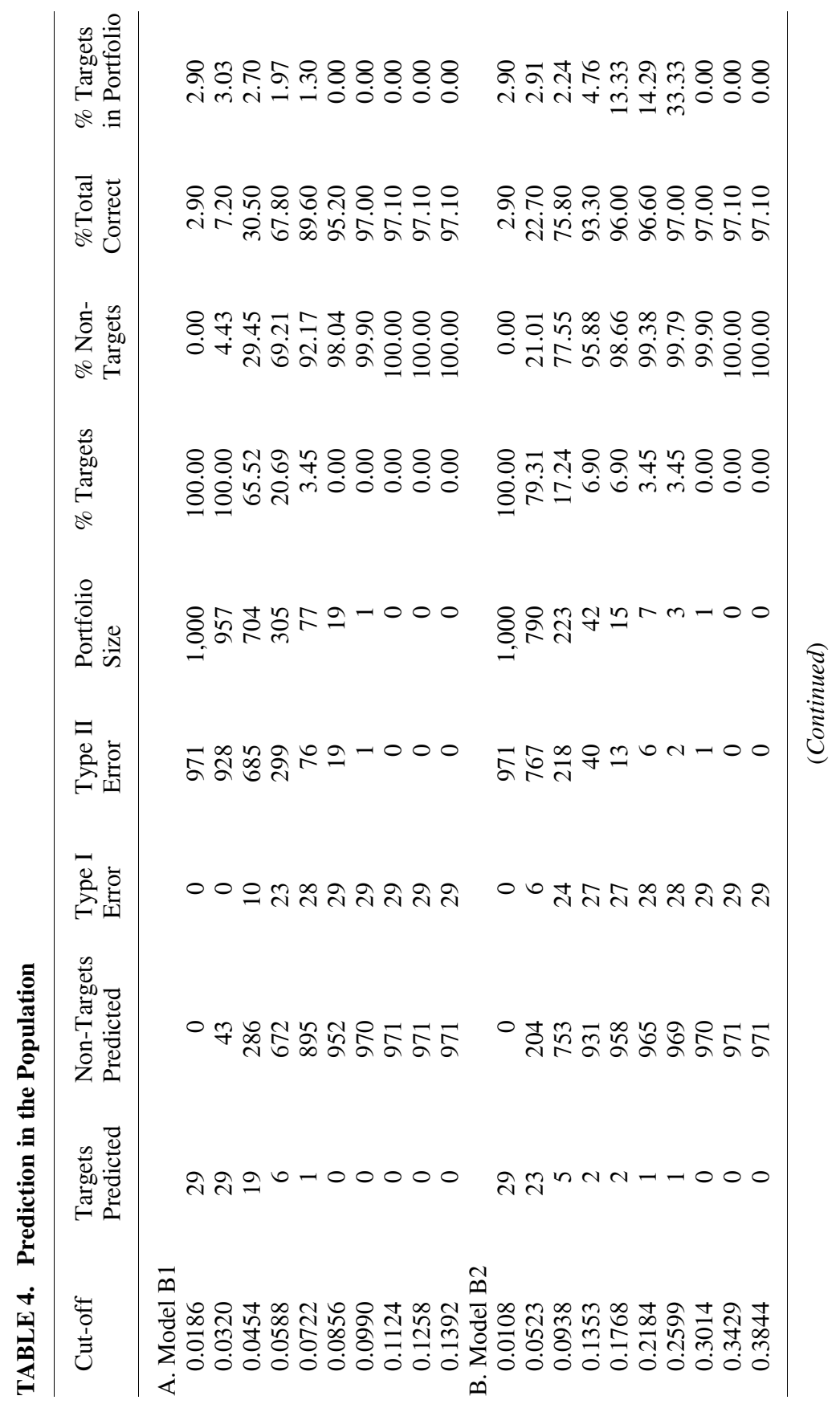




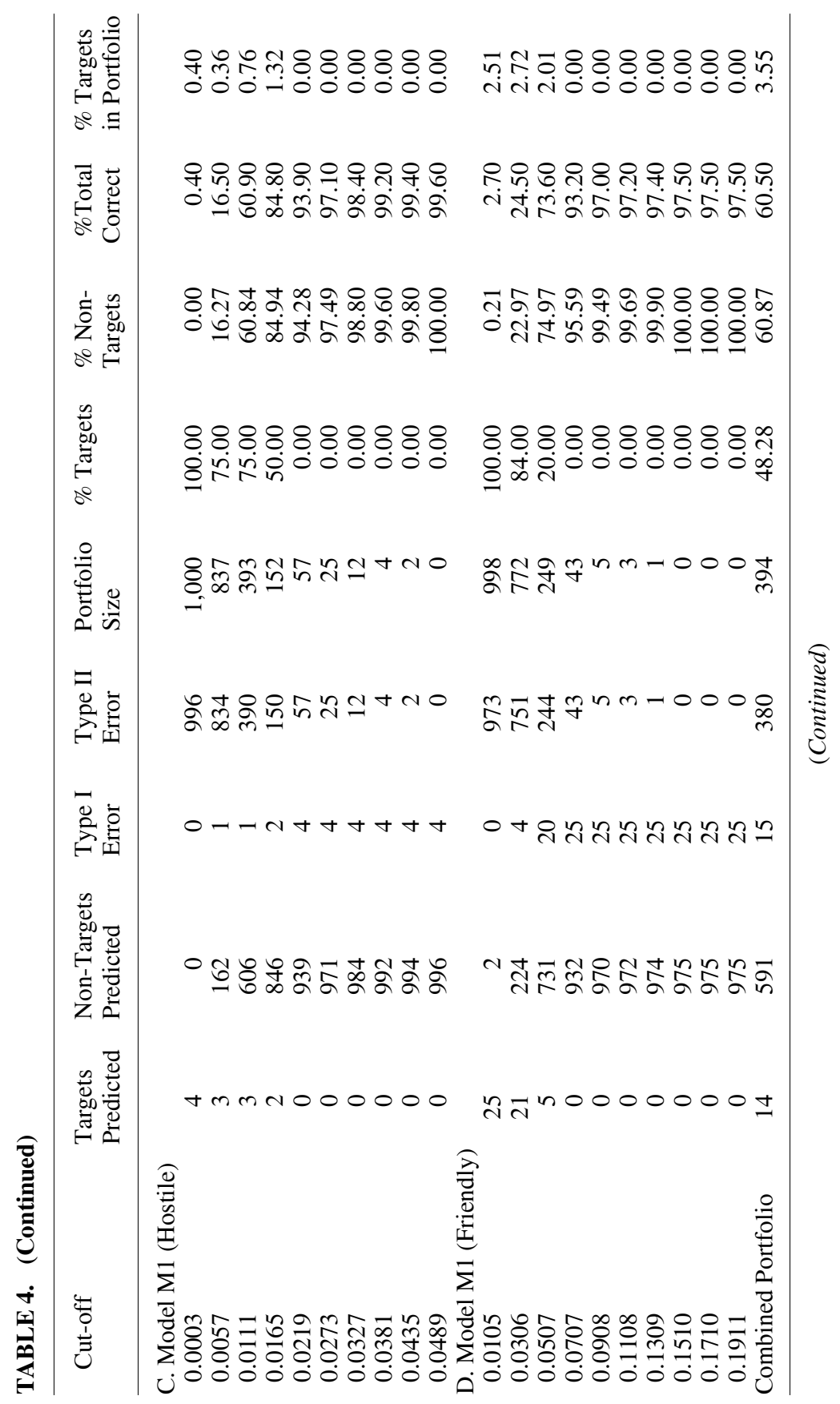




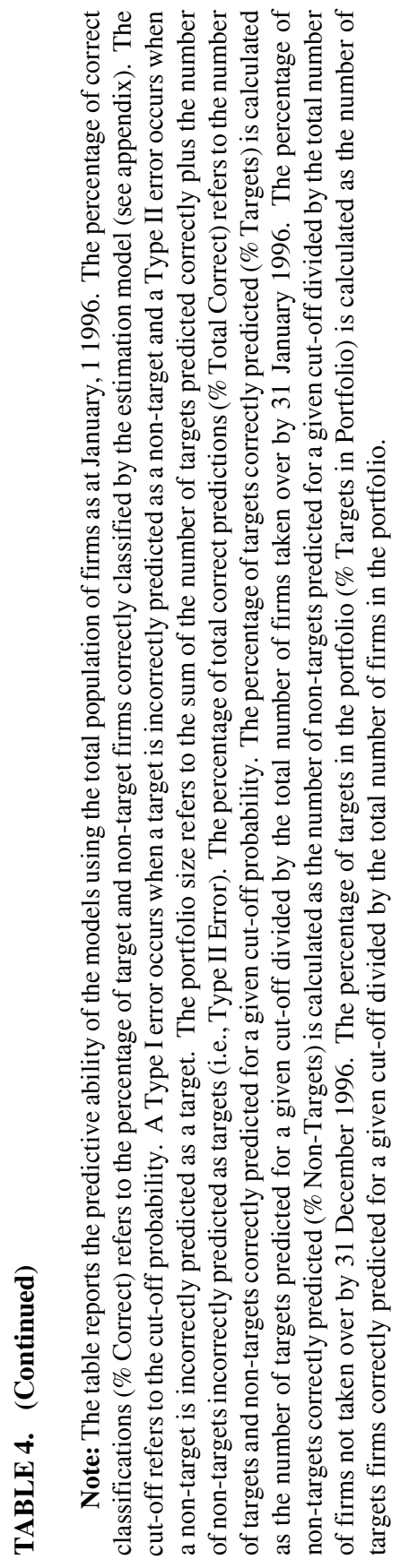


magnitude of the abnormal returns is quite high, ranging from a statistically insignificant 6-7\% over a 12-month holding period to a statistically significant $17 \%$ over a 36 -month holding period. The choice of control benchmark used in calculating abnormal returns has little impact on our conclusions, indicating that the methods used are fairly robust.

In order to cast some light on why the multinomial models perform better than the binomial models, we further examine the composition of the portfolios created using model M2 and M1 for hostile takeovers. Of the 117-firms identified by model M2 to be potential hostile targets, table 4 (panel E) indicates that only 2 are targets. However, 5 additional firms misclassified by the model as non-targets (type II error) are actually friendly targets. So, the portfolio actually contains 7 targets and 110 non-targets misclassified as targets. The BAHAR generated by the 7 targets over the 12 -month holding period amounts to $22.3 \%$ using the size only benchmark and $20.8 \%$ using the size/market-to-book benchmark. However, the 110 -firms misclassified as hostile targets actually generated BAHAR of $5.8 \%$ and $5.6 \%$, respectively, using size and size/market-to-book benchmarks, resulting in an overall portfolio BAHAR of $7 \%$ over the 12 -month holding period.

Surprisingly, model M1 failed to generate positive abnormal returns, even though it has a higher proportion of target firms. Of the 393-firms identified by the model to be hostile targets, table 4 (panel C) indicates that only 3 were hostile targets. However, similar to model M2, 11 additional firms that were misclassified by model M1 as non-targets were actually friendly targets, giving a portfolio of 14-targets and 380 non-targets misclassified as targets. The 14-targets generated BAHAR of approximately $30 \%$ over a 12-month holding period using a size/market-to-book benchmark. However, unlike Model M2, the 380 non-targets generated losses of approximately $3 \%$, giving rise to an overall negative portfolio BAHAR.

The losses experienced by the non-targets misclassified as targets by model M1 can either be attributed to their larger number (380 versus 110 for model M2) or to some other factor, such as the model picking-up poorer performers. To test this, we create a portfolio of similar size as model M2 by applying a higher cut-off to model M1. At the 4th decile (see table 4, panel C), model M1 correctly predicts 2 targets and misclassifies 150 non-targets as targets. This give a 
portfolio of 152 firms, closer to the 117-firm portfolio of model M2. However, as well as predicting 2 hostile targets, the model also predicts 3 friendly targets as hostile, giving a total of 5 targets in the portfolio. These targets generate significant BAHAR over a 12-month holding period of $33 \%$ using a size/market-to-book benchmark. The non-targets generate losses of approximately $3.5 \%$, again using the size/market-to-book benchmark. Overall, the portfolio generates insignificant losses of approximately $2 \%$ over a 12 -month holding period. Clearly, the losses generated by the non-targets misclassified as targets by model M1 are attributable to factors other than their larger number. The positive BAHAR generated by the non-targets misclassified as targets by model M2 is difficult to explain. Maybe the inclusion of firm-specific and industry-specific effects in model M2, giving rise to greater significance and explanatory power, has generated a model capable of identifying firms with superior performance compared to firms of similar size and market-to-book ratios.

\section{Summary and Conclusions}

Research in takeover prediction has generally applied statistical models that fail to account for possible differences between takeover targets. Morck et al. (1988) find that hostile and friendly takeover targets differ, with hostile (friendly) targets having characteristics that suggest a disciplinary (synergistic) motive. Ignoring these differences through the use of a binomial framework is likely to result in poorer predictive performance. This paper addresses this issue by employing a multinomial framework, in which hostile and friendly takeovers are predicted separately. The results confirm earlier results that hostile and friendly targets do indeed differ in terms of several characteristics, most notably firm size; see Powell (1997). Furthermore, compared to the binomial models, the results show that the use of a multinomial framework improves the models' significance and explanatory power. The multinomial models also predict a higher proportion of targets correctly, attributable to predicting hostile and friendly targets separately.

The paper tests the models in an investment portfolio setting where firms predicted as targets are invested in. While the binomial models 
earn buy-and-hold abnormal returns insignificantly different from zero using a size/market-to-book benchmark, the multinomial models generate significant and positive buy-and-hold abnormal returns when a strategy of predicting hostile targets only is adopted. Further investigation into the composition of the hostile multinomial portfolio reveals that while hostile targets correctly predicted by the model generate large positive abnormal returns (as expected), firms misclassified as hostile targets also earn positive abnormal returns. This is in contrast to the binomial and friendly multinomial portfolios, in which large positive target abnormal returns are diminished completely by the negative abnormal returns generated by the greater number of non-targets misclassified as targets.

One possible explanation for this finding is that the binomial and friendly multinomial models pick up poorly performing firms, who continue to perform poorly over the portfolio holding period. This is not surprising since the characteristics of takeover targets in general, and friendly takeovers in particular, are similar to firms in financial distress (i.e., smaller in size, lower liquidity and higher leverage). Hostile targets, on the other hand, are larger in size, so the multinomial model, by design, 'filters out' firms that are more likely to be in financial distress, giving rise to a portfolio with positive abnormal returns. The results from the paper help to highlight potential pitfalls in using a binomial framework to model takeovers with a view to forming an investment strategy.

\section{Appendix}

The appendix reports the optimal cut-off probability and within sample discrimination ability of the models (in bold type). A type I error occurs when a target is misclassified as a non-target and a type II error occurs when a non-target is misclassified as a target. The percentage of total correct classifications (\% total correct) refers to the percentage of target and non-target firms correctly classified by the model. The percentage of targets in the portfolio (\% targets in portfolio) is calculated as the number of targets firms correctly classified by the model divided by the total number of firms in the portfolio (i.e., the sum of the number of targets correctly classified and type II error); see appendix table. 


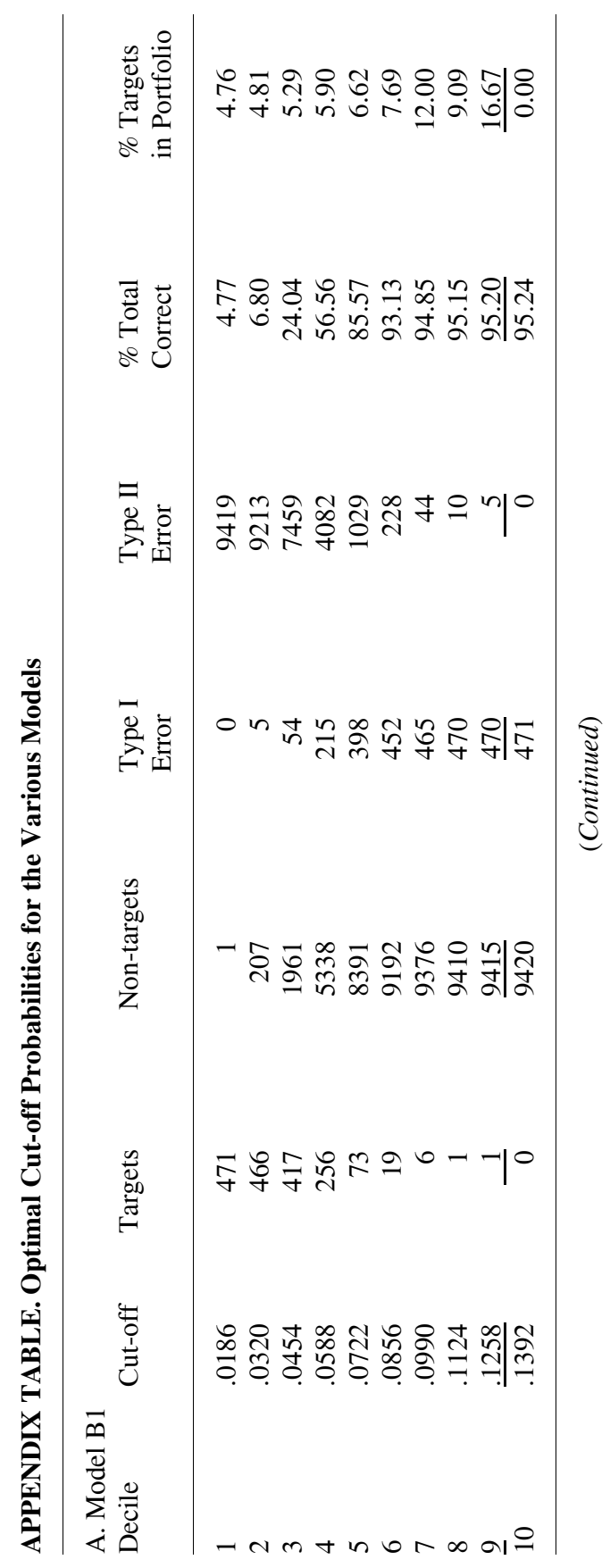




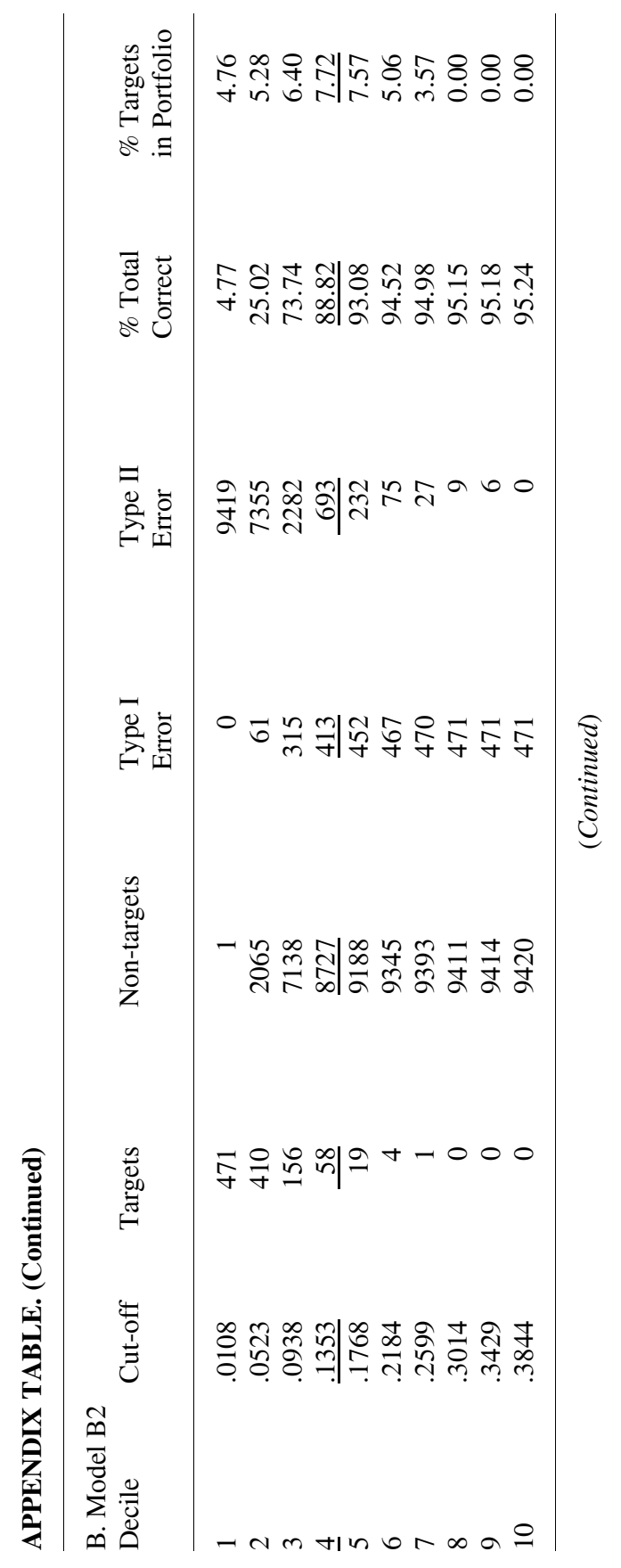




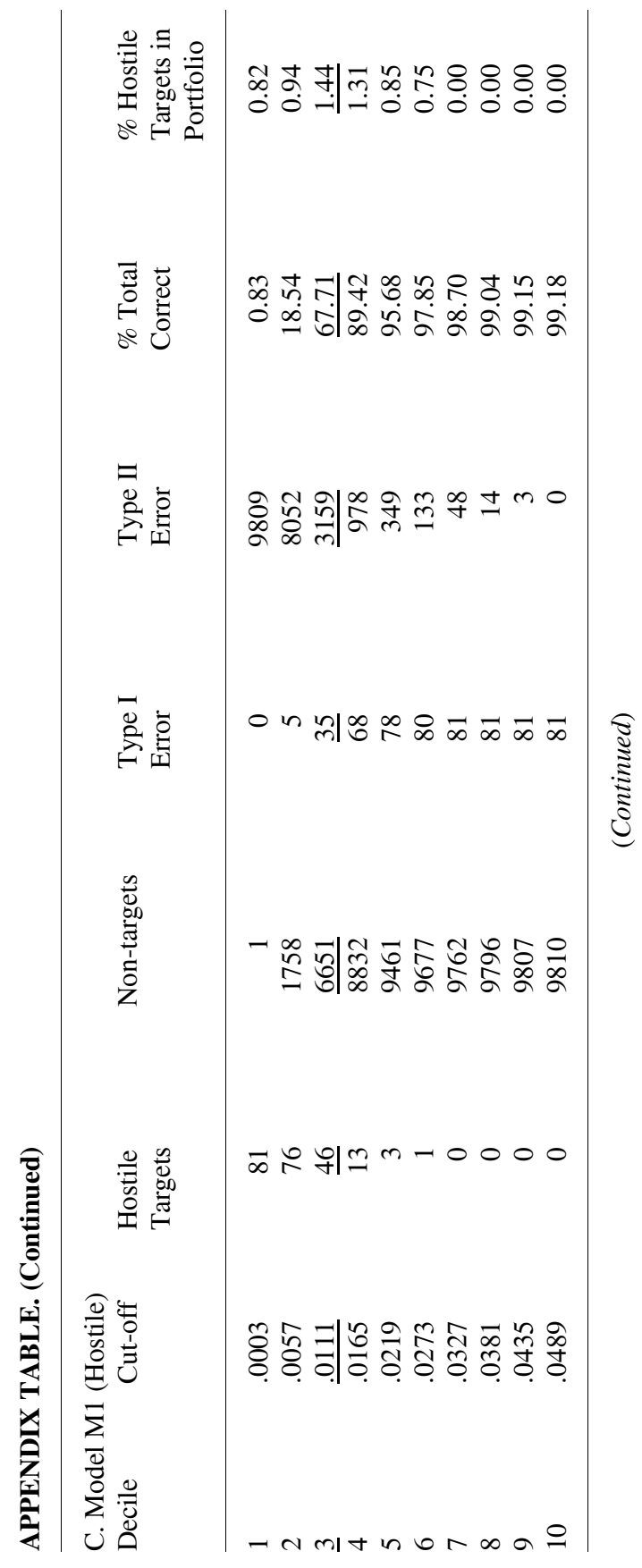




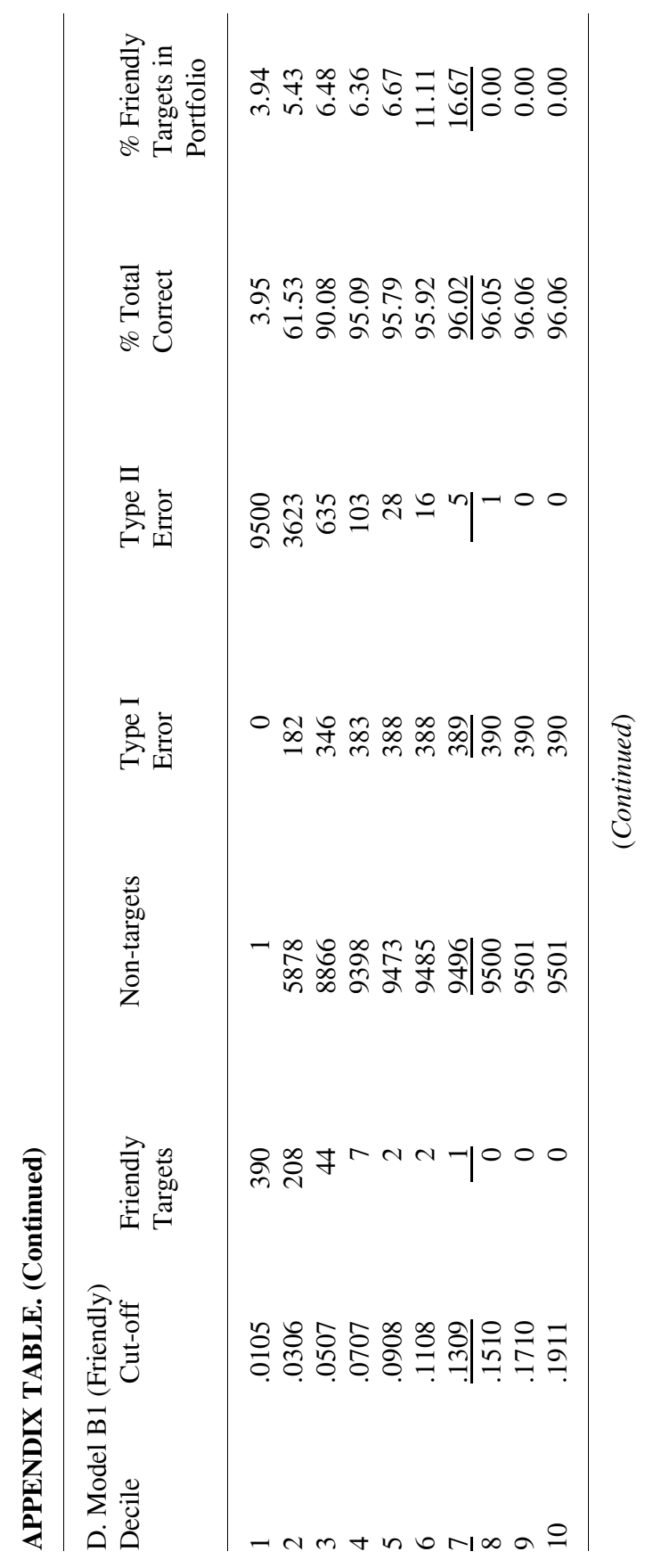




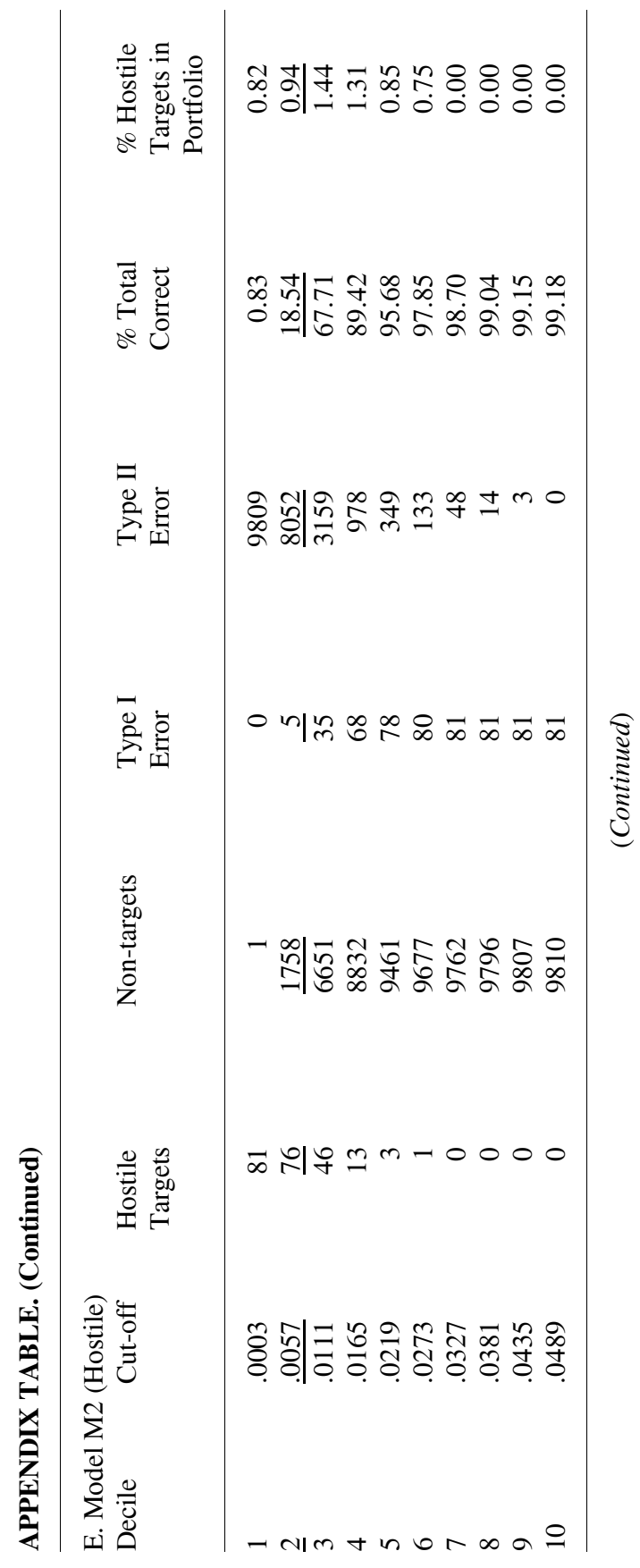




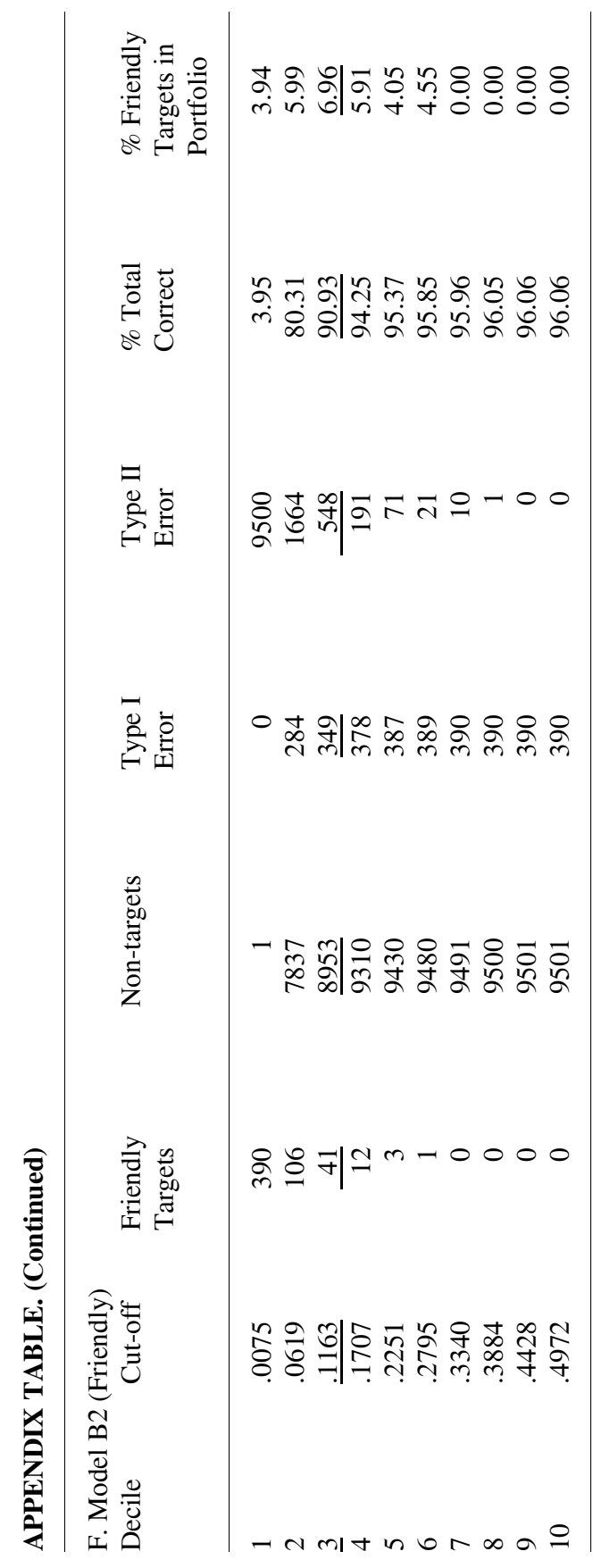




\section{References}

Ambrose, B.W. 1990. Corporate real estate's impact on the takeover market. Journal of Real Estate Finance and Economics 3: 307-322.

Ambrose, B.W., and Megginson, W.L. 1992. The role of asset structure, ownership structure, and takeover defenses in determining acquisition likelihood. Journal of Financial and Quantitative Analysis 27: 575-89.

Amit, R.; Joshua L.; and Zarowin, P. 1988. A classification of mergers and acquisitions by motives: Analysis of market responses. Contemporary Accounting Research 6: 143-158. 1988.

Asquith, P. 1983. Merger bids, uncertainty and stockholder returns. Journal of Financial Economics 11: 51-83.

Banz, R.W. 1981. The relationship between return and market value of common stock. Journal of Financial Economics 9: 3-18.

Barber, B., and Lyon, J. 1997. Detecting long-run abnormal stock returns: The empirical power and specification of test statistics. Journal of Financial Economics 43: 341-372.

Barber, B.; Lyon, J.; and Tsai, C. 1999. Improved methods for tests of long-run abnormal stock returns. Journal of Finance 54: 165-201.

Barnes, P. 1990. The prediction of takeover targets in the UK by means of MDA. Journal of Business Finance and Accounting 17: 73-84.

Barnes, P. 1998. Why do bidders do badly out of mergers? Some UK evidence. Journal of Business Finance and Accounting 25: 571594.

Barnes, P. 1999. Predicting UK takeover targets: some methodological issues and an empirical study. Review of Quantitative Finance and Accounting 12: 283-301.

Cosh, A., and Guest, P. 2001. The long run performance of hostile takeovers: UK evidence. ESRC Centre for Business Research Working Paper No. 215: University of Cambridge.

Dahya, J., and Powell, R.G. 1998. Ownership structure, managerial turnover and takeovers: Further UK evidence on the market for corporate control. Multinational Finance Journal 2: 62-83.

Dietrich, J., and Sorensen, E. 1984. An application of logit analysis to prediction of merger targets. Journal of Business Research 12: 393-402.

Eddey, P. 1991. Corporate raiders and takeover targets. Journal of Business Finance and Accounting 18: 151-71.

Fama, E., and French, K. 1992. The cross-section of expected stock returns. Journal of Finance 47: 427-465.

Franks, J.R., and Harris, R.S. 1989. Shareholder wealth effects of corporate takeovers: The UK experience 1955-85. Journal of Financial Economics 23: 225-49.

Franks, J.R., and Mayer, C. 1996. Hostile takeovers and the correction of 
managerial failure. Journal of Financial Economics 40: 163-181.

Greene, H. 1991. Limdep Version 7.0: User's Manual and Reference Guide. Econometric Software Inc.

Hasbrouck, J. 1985. The characteristics of takeover targets: q and other measures. Journal of Banking and Finance 9: 351-62.

Jensen, M.C. 1986. Agency costs of free cash flow, corporate finance and takeovers. American Economic Review 76: 323-29.

Jensen, M.C., and Ruback, R.S. 1983. The market for corporate control: The scientific evidence. Journal of Financial Economics 11: 5-50.

Kennedy, V.A., and Limmack, R.J. 1996. Takeover activity, CEO turnover, and the market for corporate control. Journal of Business Finance and Accounting 23: 267-93.

Kothari, S.P., and Warner, J.B. 1997. Measuring long-horizon security performance. Journal of Financial Economics 43: 301-39.

Lehn, K., and Poulsen, A. 1989. Free cash flow and stockholder gains in going private transactions. Journal of Finance 44: 771-87.

Levine, P., and Aaronovitch, S. 1981. The financial characteristics of firms and theories of merger activity. Journal of Industrial Economics 30: 149-72.

Maddala, G.S. 1983. Limited Dependent and Qualitative Variables in Econometrics. Econometric society monographs. Cambridge: Cambridge University Press.

McFadden, D. 1974. Conditional Logit Analysis of Qualitative Choice Behaviour. In P. Zarembka (ed). Frontiers in Econometrics New York: Academic Press.

Morck, R.; Schleifer, A.; and Vishny, R. 1988. Characteristics of targets of hostile and friendly takeovers. In A.J. Auerbach (ed). Corporate Takeovers: Causes and Consequences. Chicago: University of Chicago Press.

Palepu, K.G. 1986. Predicting takeover targets: A methodological and empirical analysis. Journal of Accounting and Economics 8: 3-35.

Platt, H.D.; Platt, M.B.; and Pedersen, J.G. 1994. Bankruptcy discrimination with real ratios. Journal of Business Finance and Accounting 21: 491-511.

Platt, H.D., and Platt, M.B. 1990. Development of a class of stable predictive variables: The case of bankruptcy prediction. Journal of Business Finance and Accounting 17: 31-51.

Powell, R.G. 1997. Modelling takeover likelihood. Journal of Business Finance and Accounting 24: 1009-30.

Powell, R.G. 2001. Takeover prediction and portfolio performance: A note. Journal of Business Finance and Accounting 28: 993-1011.

Powell, R.G., and Stark, A. 2003. Does operating performance increase post-takeover for UK takeovers? A comparison of performance measures and benchmarks. Journal of Corporate Finance, forthcoming.

Schwert, G. 2000. Hostility in Takeovers: In the eyes of the beholder? Journal 
of Finance 55: 2599-2640.

Stulz, R.M., and Johnson, H. 1985. An analysis of secured debt. Journal of Financial Economics 14: 501-21.

Theodossiou, P.; Kahya, E.; Saidi, R.; and Philippatos, G. 1996. Financial distress and corporate acquisitions: Further empirical evidence. Journal of Business Finance and Accounting 23: 699-719.

Wansley, J.W.; Roenfledt, R.L.; and Cooley, P.L. 1983. Abnormal returns from merger profiles. Journal of Financial and Quantitative Analysis 18: 149-62. 